Training Crisis in Health Psychology

The Training Crisis in Health Psychology in Australia

Paul R Martin ${ }^{1}$, Rochelle Cairns ${ }^{2}$, Helen Lindner ${ }^{3}$, Jeannette Milgrom ${ }^{4}$, Shirley Morrissey ${ }^{1}$, Lina A Ricciardelli ${ }^{5}$

\footnotetext{
${ }^{1}$ Griffith University

${ }^{2}$ Austin Health

${ }^{3}$ Australian Psychological Society

${ }^{4}$ University of Melbourne

${ }^{5}$ Deakin University
}

Corresponding author: Professor Paul R Martin, School of Applied Psychology and Behavioural Basis of Health Research Centre, Griffith University, Mt Gravatt Campus, 176 Messines Ridge Road, Mt Gravatt, Queensland 4122, email paul.martin@griffith.edu.au, telephone 073735 3322, fax 0737353399. 
Training Crisis in Health Psychology

\begin{abstract}
This paper begins with a brief history of the emergence of health psychology, discussing the nature of heath psychology, and the crisis in health that drives the need for more health psychologists. It then proceeds to discuss training in health psychology in Australia at both undergraduate and postgraduate levels. To provide a context for considering ways forward, the history of training in health psychology in Australia is reviewed followed by examination of equivalent training overseas. Reviewing these literatures revealed that in Australia only five universities offer a compulsory stand-alone course in health psychology in the first three years of the undergraduate degree. As many as 11 Australian universities have offered postgraduate training in health psychology, but this number has fallen to only three universities currently. Recommended goals and strategies for increasing postgraduate training in health psychology are offered related to: (i) increasing demand from applicants for postgraduate programs in health psychology; (ii) increasing employment opportunities for health psychologists in the public and private sectors; (iii) increasing government funding for postgraduate professional programs; (iv) development of alternative training options; and (v) increasing attractiveness of existing training options.
\end{abstract}

Key words: Australia, biopsychosocial model, health psychology, historical perspective, international perspective, training 
Training Crisis in Health Psychology

The research, teaching and practice of the discipline of health psychology started in the middle to late 1970s in the USA. Health psychology developed in the context of the biopsychosocial model, first articulated by the American psychiatrist George Engel in 1977 (Engel, 1977). This model was proposed in opposition to the prevailing reductionist singlefactor biomedical model, and was based on the assumption that health and illness are a consequence of the interplay of biological, psychological and social factors.

The Division of Health Psychology of the American Psychological Association (APA) was established in 1978, and the European Health Psychology Society was established in 1986. These professional groupings were joined by the establishment of the College of Health Psychologists of the Australian Psychological Society (APS) and the Division of Health Psychology of the British Psychological Society (BPS) both in 1997. The first textbook in health psychology was published in 1979 (Stone, Cohen, \& Adler, 1979), and the first journal was established by APA in 1982. Health psychology has been reported to be one of the fastest growing areas of research, training and practice in psychology in the United Kingdom (UK) and North America (Weinman, 2011).

\section{What is health psychology?}

Health psychology covers the theories and practice for the diagnosis, treatment and management of illness cognitions, behaviours, social and emotional factors of health problems, including chronic pain and headache/migraine, obesity, diabetes, cancer, sleep disorders, prenatal and maternal health, and sexual health. Health psychology also is the behavioural science of population and preventive health concerns, including smoking, sedentary behaviours, sun protection and risk-driving behaviours. Health psychology includes the science of the prevention of chronic disease and injury, and the reduction of the impact of chronic disease and injury. Health psychology has contributed to the evidence for bestpractice to facilitate adherence to health-focused interventions. 
Training Crisis in Health Psychology

\section{What is the work of health psychologists?}

The APS College of Health Psychologists emphasises that health psychologists specialise in understanding the relationships between psychological factors, health and illness. The College specifies that health psychologists receive training in two main areas: health promotion (prevention of illness and promotion of healthy lifestyles); and clinical health (application of psychology to illness assessment, treatment, and rehabilitation).

Ogden (2012) described health psychologists training in terms of a biopsychosocial approach to physical health and illness, which directs assessment, treatment and prevention of health concerns to factor in biological processes (e.g., a virus, tumour), psychological processes (e.g., stress, thoughts and beliefs about illness and health, behaviours such as sleeping, smoking and exercise), and social processes (e.g., gender, age, socioeconomic status, culture and ethnicity).

Health psychologists are also trained in health promotion, health policy, epidemiology, and evidence-based interventions for the prevention of physical illness or changing health behaviours that place individuals at risk of developing diseases. Training to become a registered health psychologist in the USA, Europe and Australia requires a comprehensive knowledge of the interaction between disease symptoms, medications and psychological and social functioning. Health psychology treatment formulations include the patient's pharmacological and medical experiences. Health psychologists have specific skills to diagnose and treat psychological factors such as unhelpful thoughts about health and disease management, problem health behaviours, negative emotions about illness and functionality, and poor social and work interactions that impede positive physical health outcomes.

\section{The health crisis}

The personal, social and health care system burden of chronic diseases (e.g., cardiovascular disease, type 2 diabetes, asthma, and cancers), unhealthy behaviours (e.g., 
Training Crisis in Health Psychology

smoking, sedentary behaviour, and drink-driving), and physical conditions (e.g., obesity, insomnia), have driven government health priorities in Australia and across the world. In the thirteenth biennial health report of the Australian Institute of Health and Welfare, it was identified that despite Australians enjoying one of the highest life expectancies, high levels of immunisation and falling smoking levels, when compared to other Organisation for Economic Co-operation and Development (OECD) countries, Australia had one of the highest rates of obesity, and that the rate of diabetes had doubled (Australian Institute of Health and Welfare, 2012a). The National Preventative Health Taskforce (Moodie et al., 2009) specifically identified three health priority targets of obesity, tobacco and alcohol, in the National Preventative Health Strategy - the roadmap for action document. Health status on these three targets is directly related to an individual's behaviour.

Ten years ago the World Health Organization (2003) reported that translating knowledge and/or intention into sustained health behaviour change for many people requires specific health psychological interventions. This report concluded:

"The importance of psychological and behavioural interventions has been stressed as a result of the growing recognition that knowledge alone is insufficient to produce significant changes in behaviour.” (p. 79)

This statement underpins the notion that individuals at risk of developing preventable diseases need to be educated in what they should be doing, and to have available interventions aimed at increasing the desire to want to change, and at reducing psychological barriers to long-term health behaviour change. Health psychology interventions in both health promotion and clinical health are vital for positive outcomes. The need for health psychology was evident in the Australian National Preventive Health Agency publication: the National Preventive Health Research Strategy 2013-2018 (ANPHA, 2013). This document identified health behaviours and psychological factors as significant determinants of health (p. 9). 
Training Crisis in Health Psychology

Long-term health behaviour change is problematic for those with chronic conditions who are required to adhere to medical advice with respect to a variety of behaviours including lifestyle changes, medication, self-monitoring and appointments. Research into people in developed countries with chronic disease (e.g., type 2 diabetes) shows that adherence to medical regimens for self-management is exceedingly poor, at approximately 50\%. Research into adherence in consumers with chronic conditions led Haynes, McKibbon and Kanani (1996) to conclude, and WHO to concur (2003, p. 23), that:

“...increasing the effectiveness of adherence interventions may have far greater impact on the health of the population than any improvement in specific medical treatments.”

The complexity of psychological factors affecting the likelihood of adherence to medical regimens highlights the need for the inclusion of health psychologists in healthcare teams. Health psychologists are trained, for example, to identify relevant barriers to adherence and to intervene to facilitate behaviour change. In order to address the range of psychological factors inherent in adjusting to chronic illness, it is necessary to increase access for consumers to the workforce of health psychologists who have an accredited level of knowledge and skill in health psychology.

\section{Why do we need health psychologists?}

There is international evidence that effective health care systems need a workforce of health psychologists. For example, the Wanless Report (2004), which assessed the economic viability of the UK National Health Service (NHS), reported that the current trend for increasing unhealthy lifestyle behaviours was so steep that the British health care system was in danger of collapse under the burden of increasing demand. The report recommended that the only way the system would be able to cope was by reversing this trend. There is a large body of evidence that demonstrates the efficacy of health psychology in assisting people to change their behaviour for positive health outcomes. 
Training Crisis in Health Psychology

In Australia and internationally, health psychology is a highly valued and growing field which is recognised as a critical force in addressing the burden of chronic illness, as well as the economic and social impact of ageing populations. Health Psychology has been instrumental in reducing the rate and impact of tobacco smoking, alcohol use, obesity, cardiovascular disease, cancer, diabetes, and road traffic accidents (Toumbourou, 2010). Health psychology provides a cost-effective approach to promoting improved outcomes for individuals, communities and health care systems.

Research has shown, however, that the UK NHS and other health systems in western nations, will fail to deliver improved health to future generations if nothing is done to reduce obesity, alcohol overuse, cigarette smoking, and to increase levels of physical activity, and health psychologists are critical in this process (Australian Institute of Health and Welfare, 2012b; Naylor et al., 2013; NHMRC, 2012; NHPAC, 2006; Wanless Report, 2004). Based on the National Preventative Health Taskforce goals (NPHT, 2010), the aim is to assist within the next 7 years, over 17 million people in Australia to change health behaviours to reverse the rise in overweight and obesity, and reduce tobacco use and alcohol misuse. Unfortunately, the Australian higher education system, which is currently only graduating around 10 students from accredited health psychology programs per year, is not training sufficient health psychologists to meet this need (Psychology Board Australia, 2013).

\section{Training in Health Psychology in Australia, Past and Present}

\section{Health psychology training and the course accreditation guidelines}

Despite psychology being legislated under health legislation with graduates from psychology programs being eligible for registration under this legislation, health psychology has not to date been considered a "core topic in the discipline” of psychology (see Australian Psychology Accreditation Council, APAC, Standards, 2010, section 3.17, p. 41). This has resulted in universities being able to decide whether or not to include this content in their undergraduate psychology programs. Similarly, while the current accreditation standards require undergraduate students to apply their knowledge of legislative frameworks such as 
Training Crisis in Health Psychology

privacy and human rights, and apply their knowledge of major areas of applied psychology (e.g., clinical, organisational), there is no requirement for students to apply their knowledge of health (see APAC Standards, section 3.17, p. 42). When observing the requirements for the accreditation of fourth year programs, again there is no reference to health psychology content. Indeed the reference to students gaining "advanced theoretical knowledge in some of the core research areas of the discipline” refers back to the core topics listed in section 3.17 (APAC Standards, 2010, section 4.14, p. 44). Undoubtedly, the lack of prescription of any health psychology content has been due to a prevailing attitude amongst those involved in developing and revising Standards for Psychology programs, not to be overly prescriptive. Nevertheless, the result has been that programs have not been required to offer any core courses in health psychology and therefore only those universities that can offer health psychology as an elective have been able to do so.

What is encouraging, however, is that in the current Consultation Draft and review of the APAC standards, ‘psychology and well-being' as distinct from 'psychological disorders' will be required as discipline knowledge (APAC, 2012, Appendix A, A1.2). If the proposed change to the wording for required content is accepted then psychology programs will need to demonstrate how every graduate from an undergraduate degree in psychology is able to achieve understanding in the core topic 'psychology and well-being'. While the change to discipline knowledge does not explicitly state that health psychology should be considered a core topic, the need to include 'psychology and well-being' may encourage more programs to include a compulsory course in health psychology at second or third year.

\section{Undergraduate courses in health psychology at Australian universities}

In early 2013, websites of all Australian universities offering accredited programs in psychology were explored to ascertain whether health psychology was taught as a stand-alone course/subject/unit or embedded in other courses/subjects/units. In addition, where 
information was not easy to locate regarding course structure, follow-up emails and/or phone calls were made to clarify whether any health psychology content was offered in the programs. In total, the websites of 36 publicly-funded universities, two private universities and two private education providers were explored. Table 1 provides a summary of where health psychology is currently being taught in Australia in undergraduate courses.

As can be seen from Table 1, despite graduates from psychology programs being eligible for registration as health practitioners, only five universities offer a compulsory stand-alone course in health psychology somewhere in the first three years of the undergraduate degree. Where health psychology content is embedded in other courses, this is typically in year one foundation or introductory courses. While another 23 higher education providers (57.5\%) also offer at least one elective course in health psychology in the second or third year of their degrees, with at least three of these universities offering more than one elective course in health psychology or closely related areas, we were unable to find any health psychology content in psychology programs for four universities. In addition, only one university requires health psychology as a compulsory course in fourth year, and only six universities offer an elective course at the fourth year level.

We contend that the lack of emphasis on health psychology in the undergraduate program has serious consequences. First, other disciplines in health who could enrol in a health psychology course are not able to do so, reducing the visibility of psychology among other health professions. Second, graduates from psychology programs are ill-prepared to work in the health field at the end of their $4^{\text {th }}$ year degrees despite being eligible to register as health practitioners (provisional psychologists). Third, the lack of courses in undergraduate programs leads to a lack of interest in research at $4^{\text {th }}$ year or at the postgraduate level, thus reducing Australian psychologists' contribution to the field of health psychology. Fourth, the lack of courses in undergraduate programs leads to a reduced demand for postgraduate 
Training Crisis in Health Psychology

courses/training in health psychology, which then leads to a reduction in programs being offered and a resultant lack of appropriately qualified health psychologists in Australia.

Postgraduate programs in health psychology at Australian universities, in the past and present

Accredited postgraduate professional psychology programs in Australia from 1998 when the College of Health Psychologists began its course approval function, are presented in Table 2. To date, a total of 11 universities have offered 18 accredited health psychology programs, but currently, only three universities (four programs) are offering such programs.

In an article analysing trends in accredited postgraduate professional programs between 2006 and 2010, Voudouris and Mrowinski (2010) concluded “The data reveal an alarming net decrease of 49 postgraduate professional degrees across Australia during the five year period, despite 11 new degrees being opened.” The result is that currently 37 higher education providers offer accredited programs in clinical psychology, on the one hand, whilst only one university offers a sport psychology program and only two offer community psychology programs, on the other. Hence, some professional specialisations have even fewer programs than health psychology, but most universities offer clinical psychology training.

\section{Reasons for the discontinuation of postgraduate professional programs}

In reviewing the alarming drop in availability of postgraduate psychology programs among the nine postgraduate professional specialisations, Voudouris and Mrowinski (2010) pointed to the following factors:

- The introduction of two tiers of Medicare rebates for psychology services in 2006 (Better Access), led to a change in demand and changed training models.

- Reduction in funding in 2004 for Commonwealth supported postgraduate places in psychology increased pressure on Schools and Departments of Psychology as postgraduate professional training programs were underfunded. The data of Voudouris 
Training Crisis in Health Psychology

and Mrowinski (2010) indicated that the average shortfall in funding reaching Schools was $\$ 619,197$ per annum, which equated to $\$ 8,426$ per full-time equivalent student.

- Constraints to expansion across courses included lack of available fieldwork placements and qualified supervisors.

The latter point is particularly pertinent to the smaller and more recently developed professional specialisations including health psychology, and it sets up a vicious circle whereby the discontinuation of courses contributes further to the problems of running such courses due to the low numbers of potential supervisors that are available.

The decision to drop health psychology courses in the face of financial pressures may have been a cost-benefit analysis, leading to 'survival of the fittest'. Some universities found that demand dropped for health psychology courses from quality students. This was presumed to reflect not a lack of interest in health psychology but a perception that clinical qualifications would be needed to obtain positions in the public health sector, and that projected private practice income would be less due to the higher Medicare rebate for graduates of clinical courses. The recent endorsement of Health Psychology as an endorsed area of practice by the Australian Heath Practitioner Regulation Agency was a major achievement and may ultimately assist the development of new courses.

For other universities the decision to drop courses was due to other factors, such as a change of model from DPsych programs to MPsych/PhD programs, or a change in focus of the entire Department/School, for example, to specialise in a specific field such as neuropsychology/neuroscience.

As a way of stemming the imminent threat to health psychology, Dual College Accreditation templates were developed in 2000 for DPsych courses in particular, suggesting that core units be agreed upon with additional specialist units divided between Colleges. Lack of agreement revolved around the nature of the thesis, casework requirements (hours per 
Training Crisis in Health Psychology

speciality College, hours acceptable to both). Masters programs were seen as not able to accommodate the health content needed for dual accreditation.

A negative spiral has resulted from the decision to drop health psychology courses at many universities. Some have expanded clinical psychology programs, and departing staff with expertise in health psychology have not been replaced. This reduces the likelihood that these universities would resume training in this area. A significant proportion of health psychology graduates have gone on to do bridging courses, often at great expense, and with some repetition of content, in order to gain clinical psychology qualifications.

\section{A case example: Brief snap shot of a university-hospital partnership and students' experiences}

The training crisis in health psychology encourages consideration of novel models of training. One such model is described here as an example, which involves a partnership between a university and a general hospital. Also included is a brief description of the postgraduate students who were trained with this model and their relevance to the workforce.

The Doctor of Psychology (Health) Program, University of Melbourne (1999-2008), aimed to provide comprehensive training to equip graduates to work as health psychologists. As this program was offered in conjunction with the Department of Clinical and Health Psychology, Austin Hospital (now Austin Health), it drew on clinical health psychology staff with specialisation in the acute health settings. Research activities were supported by members of both the University of Melbourne and the hospital, often in co-supervision with external experts at the cutting edge of new developments in health psychology.

A broad program aimed to provide training in the application of psychology to health, health problems and understanding health care systems, based on an understanding of psychological, social and biological determinants of health and illness. The course offered: 
knowledge and intervention skills in health promotion and lifestyle risk management; health systems and health care delivery; health system intervention; basic clinical assessment skills (including health-related behaviours, beliefs, attitudes, coping styles and risk factors); core psychological treatment skills with an emphasis on cognitive-behavioural interventions (relevant to illness, adjustment, disability and rehabilitation); basic physiology, pharmacology, medical treatments and terminology. For those wishing to specialise in either clinical health psychology or population health psychology, electives and placement specialisations were offered (e.g., oncology wards or health promotion settings). Broad research training included basic research methods, epidemiology, health systems, and evaluation and treatment outcome measurement.

A brief survey of seven past students revealed that most of the respondents had a high level of desire to undertake a health psychology degree. Interestingly, less common was the reason of failing to be accepted into a clinical psychology doctoral program. The University of Melbourne degree included health promotion and clinical health placements in the first and second years, with students choosing between the two for their third (and final year) specialisation. Prior to commencing the course, some viewed the health promotion placements as less desirable than the clinical ones. Their actual experiences in their placements changed their perspectives, however, with a recognition that the skills gained during their placements enhanced their understanding of the scope of health psychology, and provided them with invaluable skills that have served them well in their careers. Those surveyed reported that they developed good networks and skills from their placements, particularly within the health promotion settings. In addition, these placements often led to part-time employment opportunities during their training and at the completion of their course. The hospital-university partnership, with placements and a portion of the coursework subjects being conducted within the hospital, was seen predominantly as advantageous, as 
students were 'linked in to a real-life working hospital' within a well-established psychology department. The links with other health professionals during the placements were seen as highly desirable, particularly the relationships with consultation-liaison psychiatry, multidisciplinary teams, and specific wards such as oncology, orthopaedics and neurology.

There were a number of industry partnerships in the course within the health promotion placements. These included placement opportunities with the Cancer Council, TAC, Vic Fit, Monash University Accident Research Centre, the Australian Drug Foundation, the Centre for Adolescent Health, the Brain Foundation and the Heart Foundation. These placements were viewed as an exciting opportunity to experience realworld health promotion work and opened the eyes of students to the scope of career possibilities. At the time the course closed, opportunities with other psychology settings were being developed to expose students to even broader paradigms and philosophies.

Graduates have followed a wide range of career paths including: working in academia; research; program design; development and evaluation; health policy and legislation; research commissioning; telemedicine; consulting in digital communications; health promotion; public health roles; clinical-health psychological therapy; supervision; teaching; training; developing and managing psychology programs and services; and working in private practice. These roles have taken place in hospitals, universities, governmental organisations, peak bodies, and in private settings.

Respondents' views on the future of health psychology were varied. They ranged from apprehension that the health psychology specialisation would be subsumed by clinical psychology and the breadth of training lost, to confidence that it would grow in esteem, as it has done in the USA and the UK. Respondents identified a need for health psychology to strengthen its identity in both areas of health promotion and clinical health psychology with 
Training Crisis in Health Psychology

greater integration between the two. This would ensure that health psychology exists along the continuum of ill-health to well-being.

It was an innovative approach to postgraduate education, as at the time of the degrees' development, most Health Psychology courses were based primarily in Universities. This meant that Masters and Doctoral students undertook subjects and initial placements in university clinics. The University of Melbourne Health course, being based in a Hospital, included subjects taught by medical consultants recognised as experts in their areas (e.g., respiratory, psychiatry, renal). It allowed observational and initial clinical experience with patients of the hospital who were linked in with other departments, ensuring close liaison and often co-assessment or management. This exposed students to the nature of health psychology work and the inner workings of a health system from the beginning of their training. It provided students with first-hand experience of working with people who had a wide variety of health conditions. Additionally, it encouraged students to focus attention in clinical practice or research on the health conditions in which they had a greater degree of interest. Having placements within the one organisation ensured that students could participate in service development and review over a three-year period of time. This approach to education provided postgraduate students with real-life psychology work, ensuring the transition between training and employment was as smooth as possible.

Strengthening partnerships between universities and hospitals, community health centres, or Medicare locals would provide benefits for all parties. It would increase research opportunities, provide training of a greater number of health psychologists, and strengthen the depth and breadth of health care provision for patients and their communities. All of which would serve the greater purpose of improving the health of Australians.

\section{International Perspective}


Training Crisis in Health Psychology

Given that other countries such as the UK and the USA also have highly organised systems for the accreditation of health psychology training, it is useful to compare their models and to highlight some of the ways their systems ensure greater flexibility and more opportunities for growing the profession. In the UK, specialised health psychology training can be completed through an accredited university course or through the BPS. This second option is not yet available in Australia. In the USA, much of health psychology training takes place within a clinical, counselling or educational psychology doctoral program, and this is then supplemented with a bridging program in health psychology.

The training of health psychology in Europe will also be reviewed briefly, as this provides an interesting contrast as guidelines for specialist psychologists have been devised more recently and many countries still do not have specific registration requirements for health psychologists. In addition, the European guidelines for the specialist training of psychologists do not distinguish between clinical and health psychology.

Current training for health psychologists in Australia most closely parallels training in the UK. As in Australia, 'Health Psychologist' is now a protected title in the UK and as of the $1^{\text {st }}$ July, 2009, only those registered with the Health Profession Council (HPC) are entitled to use this title. In order to be registered as a health psychologist by the HPC, students need to have completed an accredited Masters course-Stage 1 (this is similar to the first year of a Masters program in Australia, but typically consists of coursework alone) followed by an accredited Stage 2 training. In the UK, the Stage 2 training can be conducted through a university-based course or completed through the BPS. Of the 49 UK universities listed by the HPC (2013), only nine provide an approved Stage 2 training program in health psychology (i.e., Doctorate in Health Psychology) in comparison to 32 that provide Stage 2 training in clinical psychology. The BPS’s Stage 2, Qualification in Health Psychology consists of structured and assessed supervised practice and the demonstration of competence 
Training Crisis in Health Psychology

in health psychology through a portfolio of evidence and an oral examination. The introduction of such an alternative path in Australia is urgently needed as this would help alleviate our current crises in courses and health psychology workforce inadequacies.

In comparison to the UK, other European countries have a less well organised system for the accreditation of health psychology training and many countries still do not have specific registration requirements for health psychologists (Belar, McIntyre, \& Matarazzo, 2012). The Masters level of education is the typical duration of professional training in health psychology. Such specialised programs commenced in Europe in the mid-1990s with the first program at the National University of Ireland at Gallway (1994), and the second program at the University of Minho in Portugal (1996). During the last 10 years there has been an expansion of Masters programs in health psychology in other countries including France, Italy, Spain, Greece, Hungry, Romania and Bulgaria (Belar et al., 2012). In addition, EuroPsy, the European qualification standard for psychologists, launched in 2009, has outlined the requirements for specialist psychologists, which includes specialisation in clinical and health psychology (EuroPsy, 2013). This includes the completion of: (i) a postgraduate program of at least 400 hours; (ii) postgraduate experience and training for at least three years; (iii) at least 500 hours of specialised practice under supervision of a qualified supervisor, with at least 150 contact hours with the supervisor; and (iv) evidence of current specialised professional competence. However, very few graduate programs in Europe would meet these guidelines (Belar et al., 2012). It is also interesting to note that the specialisation as defined by EuroPsy does not differentiate between clinical and health psychology. While specialised training in both areas has its advantages, there is also the risk that the training becomes too broad and general, and that less emphasis is given to the specific competencies and skills of health psychologists. 
Training Crisis in Health Psychology

The training of health psychologists in the USA shares both similarities and differences with the Australian and UK models. As in Australia and the UK, the USA has a highly organised system for the accreditation of health psychology training, with board certification conducted by the American Board of Clinical Health Psychology of the American Board of Professional Psychology. Board certification involves verifying that the candidate has completed the required education, training, and experience, and also passing an oral exam to demonstrate the defining competencies required to practice as a health psychologist. Also similar to Australia and UK, specialised education and training in health psychology begins at the postgraduate level, involves supervised practice usually completed within an internship, and students complete a thesis on a health-related topic. However, a main difference is that many of the USA doctoral programs are completed within another area of psychology, usually clinical, counselling or educational psychology. This is often referred to as an "embedded" program, where much of the training is broad and general, and not specific to health psychology (Larkin, 2009). These “embedded” programs need to be supplemented by additional courses that cover the core essential knowledge and skills for health psychologists. In contrast, the focus of "exclusive” programs is fully on the professional training of health psychology across both course content and practicum.

Although not ideal, given the shortage of “exclusive” programs in Australia, we too may need to shift more to the "embedded” program type, where students complete a clinical training program and then this is supplemented by a bridging program in health psychology.

The fact that most doctoral programs in health psychology in the USA are of the “embedded” type is not surprising, as the formal application to establish health psychology as a specialised field of practice was made in 1984 by Joseph D. Matarazzo, but the APA only formally recognised "clinical health psychology” as a specialty in professional practice in 1997 (Belar et al., 2012). Moreover, the APA still only accredits doctoral programs within 
Training Crisis in Health Psychology

one of the traditional specialities of clinical, counselling or educational/school psychology (Belar, 2008). Belar (2008) notes that this may well change in the future with the recent changes in the APA accreditation policy that specify how other developed practice areas may seek accreditation. However, changing accreditation guidelines takes time, and clinical health psychology needs to compete with the well-established specialities. On the more positive side, many of the APA-accredited clinical psychology doctoral programs include a large focus on health psychology, and there are a growing number of health psychology internships listed in the Association of Psychology Postdoctoral and Internship Center where trainees obtain health-related clinical experience (Belar, 2008). The approved APA nomenclature, that is, 'Clinical Health Psychology' also needs to be noted. During the process of recognition by the APA, the term 'clinical' was added to clearly identify and separate health psychologists who work as clinicians from those who work in research (Belar et al., 2012). This has proven to be a successful move, given that many allied professions and the public better understand the term 'clinical' and often are unfamiliar with the term 'health' in this context.

\section{How Can we Get More Postgraduate Programs in Health Psychology in Australia?}

A key task is to raise the profile of health psychology with prospective postgraduate students, the medical/health professions, and the government and Health Workforce Australia (HWA) (a statutory authority that delivers a national, coordinated approach to health workforce reform). Starting with the first group, in the higher education world of 2013, no university will support the introduction of a new postgraduate program without some form of a business case being presented which includes a 'needs analysis' that addresses the demand for the program. Demand is hardly likely to exist if prospective students for such programs are unaware of health psychology or have a limited understanding of what it can offer. Hence the problem identified in an earlier section that only five out of 40 higher education providers offer standalone compulsory courses in health psychology in the first three years of the 
Training Crisis in Health Psychology

undergraduate program, and only one in fourth year. Elective courses in health psychology are more common but not universal and not completed by all students graduating from the programs. An increase in the teaching of health psychology in the undergraduate program would seem likely to increase the demand for postgraduate training.

Such an increase seems overdue. Health and well-being has always been the largest application of psychology (Martin, 2011a) but there are applications of psychological science and professional specialisations for which health is only a component or does not feature at all. However, in 2010 a fundamental change took place in Australia with respect to the regulation of psychology. Until that date psychology was regulated by State/Territory Boards whose sole mission was the regulation of psychology. From $1^{\text {st }}$ July 2010, however, psychology has been regulated by the Psychology Board of Australia as one of 14 National Boards of the Australian Health Practitioner Regulation Agency. A consequence of this change is that psychology is now referred to as a 'health profession' and is regulated within the framework of a Health Profession Agreement. There was much opposition to psychology being regulated as a health profession from the APS as psychology is viewed by psychologists as much broader than health. But the changes in regulation happened anyway. The implications of this change are more than semantic. For example, training in the disciplines regulated by the 14 Boards is now required to prepare graduates for practising as health practitioners. To coin a word, the change could be referred to as the 'healthification' of psychology. Surely this argues for health psychology being listed by APAC as a 'core topic' and being referred to as an example of applying psychology?

With respect to raising the profile of health psychology with the medical/health professions, Suzanne Bennett Johnson, a distinguished health psychologist and APA President at the time, entitled one of her President’s Columns “Medicine’s paradigm shift: An opportunity for psychology” (Johnson, 2012). In this article she argued that although the 
Training Crisis in Health Psychology

biopsychosocial model dates back to 1977, the USA health care system had remained entrenched in the biomedical model until very recently.

There are a huge number of examples that could be given of the continuing dominance of the biomedical model but just one will be offered here. On the ranking of causes of disability of WHO, headache disorders are in the 10 most disabling for the two genders and the five most disabling conditions for women. Psychological treatment for headache disorders is highly effective. For example, Martin, Forsyth and Reece (2007) achieved an average reduction in headaches of $68 \%$ post-treatment and $77 \%$ at 12 -month follow-up with a cognitive behavioural approach based on a functional model. By way of comparison, Holroyd, Nash, Pingel, Cordingley and Jerome (1991) evaluated the wellestablished prophylactic medication amitriptyline and achieved a reduction in headaches of 27\%. In the days of 'evidence-based medicine', one might imagine that figures like these would mean that psychological treatment for headache disorders was commonly used but medical practitioners very rarely refer patients with headache disorders to psychologists (Latinovic, Gulliford, \& Ridsdale, 2006; Charles, Ng, \& Britt, 2005).

In summary, the biopsychosocial model should have replaced the biomedical model decades ago and let's hope that Johnson (2012) is correct that at least in the USA, the change process in near completion. Related to this change, the medical/health professions need to be made more aware of what health psychology can contribute as this will lead to more employment options for health psychologists and thereby increase demand for training.

With respect to raising the profile of health psychology with the government and HWA, politicians have control of finite resources and need to be convinced that it is worth investing in health psychology research and services. Continuing with the example of headaches, in the UK approximately 25 million work-days are lost every year due to migraine (Steiner, 2004), and it has been estimated that migraine costs Europe $€ 27$ billion per year, but 
Training Crisis in Health Psychology

only €7 million of public funding is spent on migraine research (Olesen, Lekander, AndlinSobocki, \& Jonsson, 2007). The government needs such figures brought to its attention to make the point that it is not so much that they cannot afford to spend more money on research but rather that they cannot afford not to. Again, increased government awareness should lead to more employment opportunities for health psychologists. It would also seem worth bringing to the attention of government that only three of the States/Territories in Australia have a postgraduate program in health psychology, and surely each State/Territory should have at least one program. This is particularly the case as none of the existing health psychology programs are offered in external mode.

As the single greatest barrier to offering postgraduate training in health psychology is likely to be that postgraduate professional training is usually run at a financial loss, perhaps alternative training models need more consideration. For example, offering places on a feepaying basis or providing training in health psychology in research degrees that are Commonwealth-funded and supported by scholarships.

There are other changes that would facilitate the development of more postgraduate training programs in health psychology. The Australian Qualifications Framework (AQF) was established in 2011, and included the provision for degrees called Masters Degrees (Extended). These degrees are completed in three to four years following successful completion of a 3-year degree. There is a list of five professions (medical practice, physiotherapy, dentistry, optometry, veterinary practice) for which individuals completing Masters Degrees (Extended) can use the title 'Doctor of...'. If psychology could be added to this list, as it should be (Martin, 2011b), then it would be possible to establish $3+3$ year sequences leading to the title 'Doctor of Health Psychology'. This would likely be a very popular option. It is parallel with what a number of medical schools have done since this option was available whereby instead of students completing Bachelor degrees in medicine 
Training Crisis in Health Psychology

and in surgery they complete a six-year sequence culminating in a Masters Degree (Extended) and graduate with the title 'Doctor of Medicine'.

Another change that would lead to more individuals wanting to study health psychology would be a change in the Medicare rebate system whereby health psychologists received the same rebates as clinical psychologists, that is, the higher specialist rate. Given that the number of allowable sessions of psychological treatment under Better Access was cut from 18 sessions to 10 sessions in 2013 despite a strong campaign of opposition by the APS (see http://www.psychology.org.au/newsandupdates/betteraccess/), and the deteriorating Australian economy, the difficulty of gaining specialist rebates for health psychology services cannot be underestimated. Two factors that could assist lobbying of the government, however, are firstly the low number of health psychologists relative to clinical psychologists (on the basis of full membership of the requisite APS Colleges, a ratio of approximately 1:15) so that the cost would be relatively small. Second, is that it is arguably easier to make the case for health psychology rebates given that the domain of this professional specialisation pertains to the major causes of death and disability.

\section{Conclusions}

Health psychology is now needed more than ever as a greater and greater proportion of the population die of chronic diseases related to behaviour and lifestyle. In countries like the UK and North America, the number of training programs in health psychology is increasing to meet this need. However, in Australia the reverse is happening with $78 \%$ of established programs discontinued. Table 3 contains a summary of recommended overlapping goals and strategies to build health psychology training in Australia.

The actions flagged in this paper are just some of the possible ways to reverse the decline in the number of health psychology training programs in Australia which is essential to take advantage of what Johnson (2012) has described as 'medicine's paradigm shift'. 


\section{Key points}

\section{What is already known about this topic}

- Health psychology evolved in the mid to late 1970s in the context of the development of the biopsychosocial model.

- Health psychology is now needed more than ever as a greater and greater proportion of the population die of chronic diseases related to behaviour and lifestyle (e.g., heart disease, cancer, cerebrovascular disease) rather than infectious diseases (e.g., influenza, tuberculosis, gastroenteritis).

- As many as 11 universities in Australia have offered postgraduate training in health psychology, but this number has fallen to only three universities currently, which represents a major crisis.

\section{What this topic adds}

- Recommendations to reverse this decline in numbers include raising the profile of health psychology with potential postgraduate students, the medical/health professions, and government and Health Workforce Australia.

- Also it is recommended that health psychology is designated a 'core topic' in the Australian Psychological Accreditation Council Standards, commensurate with psychology now being categorised as a 'health profession' by the regulatory authorities.

- Other recommendations include that the Medicare rebates for services in health psychology be equivalent to the rebates for services in clinical psychology, and for psychology to be added to the list of professions for which graduates of Masters Degrees (Extended) can use the title 'Doctor of (Health Psychology)'. 
Training Crisis in Health Psychology

\section{References}

Australian Institute of Health and Welfare (2012a). Australia's health 2012. Australia's health series no.13. Cat. no. AUS 156. Canberra: AIHW.

Australian Institute of Health and Welfare (2012b). Risk factors contributing to chronic disease. Cat. no. PHE 157. Canberra: AIHW.

Australian National Preventive Health Agency (2013). National preventive health research strategy 2013-2018. http://anpha.gov.au/internet/anpha/publishing.nsf/Content/6B9D43273945EB8ACA257 B9500083EDA/\$File/Research\%20Strategy\%20final_laser\%20copy.pdf

Australian Psychology Accreditation Council (2010). Rules for Accreditation and Accreditation Standards for Psychology Courses. APAC: Melbourne.

Australian Psychology Accreditation Council (2012). Accreditation Standards for Programs of Study in Psychology. APAC: Melbourne.

Belar, C. D. (2008). Clinical health psychology. Professional Psychology: Research and Practice, 39, 229-233. doi: 10.1037/0735-7028.39.2.229.

Belar, C. D., McIntyre, T. M., \& Matarazzo, J. D. (2012). Health psychology. In Weiner, I. B. (Ed.). Handbook of psychology, history of psychology. New York: Wiley.

Charles, J., Ng, A., \& Britt, H. (2005). Presentations of headache in Australian general practice. Australian Family Physician, 34, 618-619.

Engel, G. L. (1977). The need for a new medical model: A challenge for biomedicine. Science, 196, 129-136.

EuroPsy (2013). http://www.europsy-efpa.eu/about February 5, 2013.

Haynes, R. B., McKibbon, K. A., \& Kanani, R. (1996). Systematic review of randomised trials of interventions to assist consumers to follow prescriptions for medications. Lancet, 348, 383386. 
Training Crisis in Health Psychology

Health Profession Council (2013). http://www.hpc-uk.org/ January 17, 2013.

Holroyd, K. A., Nash, J. M., Pingel, J. D., Cordingley, G. E., \& Jerome, A. (1991). A comparison of pharmacological (amitriptyline HCL) and nonpharmacological (cogntive-behavioral) therapies for chronic tension headaches. Journal of Consulting and Clinical Psychology, 59, 387-393.

Johnson, S. B. (2012). Medicine’s paradigm shift: An opportunity for psychology. Monitor on Psychology, September, 5.

Larkin, K. T. (2009). Variations of doctoral training programs in Clinical Health Psychology: Lessons learned at the Box Office. Training and Education in Professional Psychology, 4, 202-211. doi: 10.1037/a0016666.

Latinovic, R., Gulliford, M., \& Ridsdale, L. (2006). Headache and migraine in primary care: Consultation, prescription, and referral rates in a large population. Journal of Neurology, Neurosurgery and Psychiatry, 77, 385-387. doi:

10.1136/jnnp.2005.073221.

Martin, P. R. (2011a). Applied psychology in the international context: What more needs to be done? In P. R. Martin, F. Cheung, M. Knowles, M. Kyrios, L. Littlefield, B. Overmier, \& J. M. Prieto, (Eds.). The IAAP handbook of applied psychology (pp. 717731). Oxford: Wiley-Blackwell.

Martin, P. R. (2011b). Clinical psychology going forward: The need to promote clinical psychology and to respond to the training crisis. Clinical Psychologist, 15, 93-102. doi: 10.1111/j.1742-9552.2011.00031.x.

Martin, P. R., Forsyth, M. R., \& Reece, J. (2007). Cognitive-behavioral therapy versus temporal pulse amplitude biofeedback training for recurrent headache. Behavior Therapy, 38, 350-363.

Moodie, R., et al. (2009). Australia: The Healthiest Country by 2020 - National Preventative Health Strategy - the roadmap for action. 
Training Crisis in Health Psychology

http://www.preventativehealth.org.au/internet/preventativehealth/publishing.nsf/Conten t/nphs-roadmap-toc

National Health Priority Action Council (NHPAC) (2006). National Chronic Disease

Strategy. Australian Government Department of Health and Ageing, Canberra.

http://www.health.gov.au/internet/main/publishing.nsf/Content/7E7E9140A3D3A3BC

CA257140007AB32B/\$File/stratal3.pdf

National Preventative Health Taskforce (2010). Australia: the Healthiest Country by 2020.

Commonwealth of Australia: Canberra. ISBN: 1-74186-727-4.

Naylor, C. et al. (2013). The Kings Fund: Ideas that change health care.

http://www.kingsfund.org.uk/sites/files/kf/field/field_publication_file/10PrioritiesFinal

2.pdf

NHMRC (2012). National Health Priority Areas (NHPAs): Available NHPA datasets.

http://www.nhmrc.gov.au/grants/research-funding-statistics-and-data/national-healthpriority-areas-nhpas

Ogden, J. (2012). Health psychology: A textbook (5th ed.). Maidenhead, UK: Open University Press.

Olesen, J., Lekander, I., Andlin-Sobocki, P., \& Jonsson, B. (2007). Funding of headache research in Europe. Cephalalgia, 27, 995-999.

Psychology Board of Australia. (31 May, 2013). Psychology Approved Programs of Study. http://www.psychologyboard.gov.au/Accreditation.aspx

Steiner, T. J. (2004). Lifting the burden: The Global Campaign against Headache. Lancet Neurology, 3, 204-205. doi: 10.1016/S1474-4422(04)00703-3.

Stone, G. C., Cohen, F., \& Adler, N. E. (Eds.) (1979). Health psychology - a handbook. San Francisco: Jossey-Bass. 
Training Crisis in Health Psychology

Toumbourou, J. (2010). The effectiveness of health psychology interventions. Available at http://www.groups.psychology.org.au/Assets/Files/coh_Psych_Effectiveness_article.pd $\underline{\mathrm{f}}$

Voudouris, N., \& Mrowinski, V. (2010). Alarming drop in availability of postgraduate psychology training. InPsych, 32, 20-23.

Wanless report (2004). Retrieved 20 February 2013 from

http://webarchive.nationalarchives.gov.uk/+/http://www.hm-

treasury.gov.uk/media/D/3/Wanless04_summary.pdf

Weinman, J. (2011). A brief history of health psychology. Retrieved 20 February 2013 from www.youtube.com/watch?v=VoKZKLlfRcs

World Health Organization (2003). Adherence to long-term therapies: Evidence for action. World Health Organization: Switzerland. Retrieved 20 February 2013 from http://whqlibdoc.who.int/publications/2003/9241545992.pdf 
Training Crisis in Health Psychology

Table 1

Breakdown of the Number of Universities or Education Providers Offering Health

Psychology as Embedded Content, Elective Course ${ }^{a}$ or Compulsory Course

\begin{tabular}{|l|c|}
\hline Health psychology in undergraduate courses & $\begin{array}{c}\text { Number of } \\
\text { universities/education } \\
\text { providers offering } \\
\text { Health Psychology }\end{array}$ \\
\hline $\begin{array}{l}\text { Years 1-3: Health psychology content embedded in core } \\
\text { undergraduate course (e.g., Introduction to Psychology) }\end{array}$ \\
\hline $\begin{array}{l}\text { Years 1-3: Health psychology offered as a standalone course and } \\
\text { taken as an elective course }\end{array}$ \\
\hline $\begin{array}{l}\text { Years 1-3: Health psychology offered as a standalone course and } \\
\text { taken as a compulsory course }\end{array}$ \\
\hline $\begin{array}{l}\text { Year 4: Health psychology offered as a standalone course and taken } \\
\text { as an elective course }\end{array}$ \\
\hline $\begin{array}{l}\text { Year 4: Health psychology offered as a standalone course and taken } \\
\text { as a compulsory course }\end{array}$ \\
\hline
\end{tabular}

a The term 'course' is used to denote any semester long stand-alone subject or unit or course that is offered by an educational provider and for which students can enrol and receive credit. 
Training Crisis in Health Psychology

Table 2

Accredited Postgraduate Professional Health Psychology Programs from 1998

\begin{tabular}{|c|c|c|c|}
\hline $\begin{array}{l}\text { Year program } \\
\text { accredited }\end{array}$ & University & Type of program & Current status \\
\hline 1999 & Deakin University & $\begin{array}{l}\text { Masters } \\
\text { DPsych (Health) }\end{array}$ & $\begin{array}{l}- \\
\text { Current }\end{array}$ \\
\hline 1998 & La Trobe University & $\begin{array}{l}\text { Masters (Health) } \\
\text { DPsych (Health) }\end{array}$ & - \\
\hline 2001 & Monash University & Masters (Health) & - \\
\hline 1998 & $\begin{array}{l}\text { Swinburne } \\
\text { University of } \\
\text { Technology }\end{array}$ & $\begin{array}{l}\text { MPsych (Health) } \\
\text { DPsych (2001) }\end{array}$ & $\begin{array}{l}- \\
-\end{array}$ \\
\hline 1998 & University of Ballarat & DPsych & - \\
\hline 2001 & $\begin{array}{l}\text { University of } \\
\text { Melbourne }\end{array}$ & DPsych & - \\
\hline 2000 & $\begin{array}{l}\text { University of } \\
\text { Southern Queensland }\end{array}$ & $\begin{array}{l}\text { MPsych (Health) } \\
\text { DPsych (Health) }\end{array}$ & - \\
\hline 2001 & Victoria University & MAppPsych (Health) & - \\
\hline 2003 & $\begin{array}{l}\text { University of } \\
\text { Newcastle }\end{array}$ & $\begin{array}{l}\text { MPsych (Health) } \\
\text { DPsych (Clinical and } \\
\text { Health) (2005) }\end{array}$ & - \\
\hline 2008 & $\begin{array}{l}\text { University of } \\
\text { Adelaide }\end{array}$ & $\begin{array}{l}\text { MPsych (Health) } \\
\text { PhD/MPsych } \\
\text { (Health) }\end{array}$ & $\begin{array}{l}\text { Current } \\
\text { Current }\end{array}$ \\
\hline 2007 & $\begin{array}{l}\text { University of } \\
\text { Queensland }\end{array}$ & $\begin{array}{l}\text { MAppPsych (Health) } \\
\text { DPsych (Clinical and } \\
\text { Health) }\end{array}$ & $\begin{array}{l}\text { Current } \\
\text { - }\end{array}$ \\
\hline
\end{tabular}

Source: APAC documentation and discussion with Schools 
Training Crisis in Health Psychology

Table 3

Summary of Recommended Goals and Strategies for Increasing Postgraduate Training Programs in Health Psychology

\begin{tabular}{|c|c|c|}
\hline Goals & Strategies & Implementation \\
\hline $\begin{array}{l}\text { Increase demand from } \\
\text { applicants for postgraduate } \\
\text { programs in health psychology }\end{array}$ & $\begin{array}{l}\text { Increase health psychology } \\
\text { content in undergraduate } \\
\text { programs }\end{array}$ & $\begin{array}{l}\text { Persuade APAC to include } \\
\text { health psychology as a } \\
\text { 'core topic' }\end{array}$ \\
\hline $\begin{array}{l}\text { Increase employment } \\
\text { opportunities for health } \\
\text { psychologists in public sector }\end{array}$ & $\begin{array}{l}\text { Raise the profile of health } \\
\text { psychology with government, } \\
\text { HWA, medical/health } \\
\text { professions }\end{array}$ & $\begin{array}{l}\text { Lobby government }{ }^{1} \text {, and } \\
\text { publication of systematic } \\
\text { reviews that establish the } \\
\text { case }\end{array}$ \\
\hline $\begin{array}{l}\text { Increase employment } \\
\text { opportunities for health } \\
\text { psychologists in private sector }\end{array}$ & $\begin{array}{l}\text { Add specialist rebates for } \\
\text { health psychology services to } \\
\text { Medicare }\end{array}$ & Lobby government $^{1}$ \\
\hline $\begin{array}{l}\text { Increase government funding } \\
\text { for postgraduate professional } \\
\text { programs }\end{array}$ & Lobbying required & Lobby government $^{1}$ \\
\hline $\begin{array}{l}\text { Development of alternative } \\
\text { training options, as has } \\
\text { occurred in Australia \& } \\
\text { overseas (e.g., BPS) }\end{array}$ & $\begin{array}{l}\text { Lobbying of APS and other } \\
\text { potential providers to offer } \\
\text { bridging courses, etc }\end{array}$ & $\begin{array}{l}\text { Persuade APS to offer such } \\
\text { programs through its new } \\
\text { Training Institute }\end{array}$ \\
\hline $\begin{array}{l}\text { Increase attractiveness of } \\
\text { existing training options }\end{array}$ & $\begin{array}{l}\text { Get psychology onto list of } \\
\text { professions for which } \\
\text { Masters Degree (Extended) } \\
\text { leads to honorary title of } \\
\text { 'doctor of...' }\end{array}$ & $\begin{array}{l}\text { Lobby Australian } \\
\text { Qualifications Framework } \\
\text { Council or Tertiary } \\
\text { Education Quality and } \\
\text { Standards Agency }\end{array}$ \\
\hline
\end{tabular}

1. The most obvious group for lobbying is the APS but there are other groups that could contribute to lobbying on particular issues including: Heads of Departments and Schools of Psychology Association; Academy of Social Sciences in Australia; Science \& Technology Australia; Allied Health Professions Australia; and Psychology Foundation of Australia. 